\title{
Successful pregnancy in maple syrup urine disease: a case report and review of the literature
}

\author{
Sarah Catharina Grünert, Stefanie Rosenbaum-Fabian, Anke Schumann, Karl Otfried Schwab, Nadja Mingirulli
} and Ute Spiekerkoetter

\begin{abstract}
Background: Maple syrup urine disease (MSUD) is an autosomal recessive disorder of branched-chain amino acid metabolism. Patients with MSUD are at risk of life-threatening metabolic decompensations with ketoacidosis and encephalopathy. These episodes are often triggered by physiological stress. Only few cases of pregnancies in MSUD mothers have been reported so far.

Case presentation: We present the favorable outcome of a pregnancy in a woman with classical MSUD. She presented in the metabolic outpatient clinic in week 7 of gestation. Branched-chain amino acid concentrations were measured at least weekly to adjust dietary leucine intake. Despite excellent compliance, leucine concentrations frequently exceeded the target value of $<300 \mu \mathrm{mol} / \mathrm{L}$ during the first trimester. From the second trimester until delivery, protein and leucine intake increased continuously to about threefold compared to prepregnancy values. To maximize patient safety during delivery and the postpartum period, a detailed plan including peripartal infusion therapy, dietary recommendations and monitoring parameters was developed. Primary Caesarean section was performed in week 38 of gestation, and the patient gave birth to a healthy girl. Lactation was successfully implemented. Leucine levels were maintained within the target range throughout the complete postpartum period. In addition to our case, we give an overview about all cases of pregnancies in MSUD mothers published so far.

Conclusions: Management of pregnancy, delivery, postpartum period and lactation may be challenging in patients with MSUD. Careful monitoring and interdisciplinary collaboration is essential to minimize the risk of metabolic crisis, especially after delivery.
\end{abstract}

Keywords: Maple syrup urine disease, MSUD, Pregnancy, Leucine tolerance, Protein tolerance, Branched-chain amino acids, Obstetrics, Metabolic disease

\section{Background}

Maple syrup urine disease (MSUD, OMIM 248600) is an autosomal recessive inborn error of branched-chain amino acid (BCAA) metabolism caused by deficiency of the branched-chain $\alpha$-ketoacid dehydrogenase complex. Mutations in 3 of four genes that encode the catalytic subunits of the enzyme complex (E1, E2, E3) have been described. MSUD is a rare disease in most populations, with incidence estimates of 1:185,000 live births $[1,2]$.

\footnotetext{
* Correspondence: Sarah.gruenert@uniklinik-freiburg.de

Department of General Pediatrics, Adolescent Medicine and Neonatology,

Medical Center - University of Freiburg, Faculty of Medicine, Mathildenstraße 1, 79106 Freiburg, Germany
}

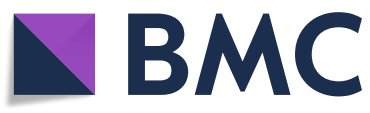

(C) The Author(s). 2018 Open Access This article is distributed under the terms of the Creative Commons Attribution 4.0 International License (http://creativecommons.org/licenses/by/4.0/), which permits unrestricted use, distribution, and reproduction in any medium, provided you give appropriate credit to the original author(s) and the source, provide a link to the Creative Commons license, and indicate if changes were made. The Creative Commons Public Domain Dedication waiver (http://creativecommons.org/publicdomain/zero/1.0/) applies to the data made available in this article, unless otherwise stated. populations due to a founder variant resulting in a frequency for classic MSUD as high as approximately one in 380 live births [3]. Diagnosis is based on the detection of markedly elevated concentrations of BCAA and alloisoleucine in plasma and urine as well as branched-chain ketoacid analogues in urine of affected individuals. Patients with MSUD are prone to metabolic crises, presenting with ketoacidosis, vomiting, poor feeding, neurological symptoms and encephalopathy, often triggered by catabolism due to intercurrent infections, surgery or excessive intake of BCAA. The toxic metabolite is leucine, and high concentrations are associated with ketosis and the risk of 
cerebral edema [4]. Although most patients manifest within the neonatal period, metabolic crises can occur at any age. Long-term treatment of MSUD includes a lowprotein diet with supplementation of a BCAA-free amino acid mixture.

Only few cases of pregnancies in MSUD patients have been reported so far [4-10]. The overall outcome seems to be favorable. Nevertheless, pregnancy can put patients at risk for decompensation due to possible hyperemesis gravidarum, catabolic stress during delivery and excessive protein turnover during the postpartum period. We report the successful outcome of a pregnancy in a 26year-old woman with classical MSUD and our experiences in the management from pregnancy to lactation. Additionally, we provide a review of the literature including all cases of pregnancies in MSUD patients published so far.

\section{Case presentation}

The patient is a 26-year-old woman who was diagnosed with classical MSUD presymptomatically within the first days of life due to an older affected brother. She has been on a low-protein diet with supplementation of a BCAA-free amino acid mixture since birth with good metabolic control and normal intellectual development. A number of short hospitalizations had been necessary during childhood because of mild metabolic decompensations during intercurrent illnesses. The highest leucine concentration ever measured was $1145 \mu \mathrm{mol} / \mathrm{L}$ within the neonatal period. Leucine tolerance prior to pregnancy was 700-800 mg per day. Genetic analysis revealed a homozygous mutation in the $B C K B H D$ gene, c.721A > T, p.K241\%.

The patient presented in the metabolic outpatient clinic as early as week 7 of gestation. This was the first pregnancy of the patient. No relevant problems such as nausea or hyperemesis gravidarum occurred during the first trimester. Pre-pregnancy weight was $74 \mathrm{~kg}$, and body mass index was $27.2 \mathrm{~kg} / \mathrm{m}^{2}$. Weight gain during pregnancy was $15 \mathrm{~kg}$ ( $0 \mathrm{~kg}$ during 1st trimester, $7 \mathrm{~kg}$ during 2nd trimester, $8 \mathrm{~kg}$ during $3 \mathrm{rd}$ trimester). Serum amino acids were monitored weekly throughout pregnancy and the diet was adapted regularly according to BCAA concentrations. Target concentrations of BCAAs were: leucine $100-300 \mu \mathrm{mol} / \mathrm{L}$, isoleucine 100 $300 \mu \mathrm{mol} / \mathrm{L}$ and valine $200-400 \mu \mathrm{mol} / \mathrm{L}$. During the first trimester, these goals were hard to achieve and leucine levels ranged between 87 and $609 \mu \mathrm{mol} / \mathrm{L}$. From the second trimester protein tolerance increased significantly to up to $2400 \mathrm{mg}(=27 \mathrm{mg} / \mathrm{kg} / \mathrm{d})$ leucine per day prior to delivery. Details of the prescribed diet including leucine intake, total protein, synthetic protein as well as isoleucine and valine supplementation are shown in Fig. 1. Additionally, examples of dietary protocols with different amounts of leucine are given in Additional file 1: Table S1, Additional file 2: Table S2, Additional file 3: Table S3. From the third month of pregnancy, a bedtime snack was introduced. The BCAA-free amino acid mixture was divided to 4 to 5 daily doses. BCAA levels during pregnancy are outlined in Fig. 2. Laboratory values including whole blood count, iron status, total protein, albumin, transaminases and creatinine were checked regularly and remained normal throughout pregnancy. A pregnancyspecific vitamin supplement containing folic acid, jodine, vitamin B1, B2, B6, B12, C, D3, E, biotin and niacin was given during the first trimester according to routine gynecological recommendations. From gestational week 15 the patient additionally received progesterone. Later in pregnancy, magnesium and iron were substituted to prevent premature contractions and pregnancy-related anemia, respectively, and omeprazole was added due to gastroesophageal reflux.

Pregnancy was uneventful, and no major problems occurred. Mild proteinuria was present within the second trimester, but resolved spontaneously. Fetal arrhythmia was noted in week 17, but considered non-pathological by a cardiologic specialist. During pregnancy the patient was followed by the metabolic team of the University Children's Hospital for treatment of MSUD in collaboration with the Obstetric Department of the University Hospital. As the patient lived quite far from the metabolic center delivery was planned as Cesaerean section to ensure maximal safety for the patient. A treatment plan was tailored for the peripartal period, including infusion therapy to prevent perioperative catabolism, dietary management and necessary monitoring of mother and child. The Cesaerean section was performed in week 38. The patient was admitted 1 day in advance, and a triple-lumen central venous catheter was inserted. Few hours before surgery, when she had to be nil per os, parenteral nutrition containing $5 \mathrm{~g}$ glucose per $\mathrm{kg}$ body weight per day (G40\%) and $1 \mathrm{~g}$ fat per $\mathrm{kg}$ body weight per day (20\% intravenous fat emulsion) was given together with $1.5 \mathrm{l}$ per day of an isotonic electrolyte infusion. Surgery was without complications, and the patient delivered a healthy female infant with a birth weight of $2795 \mathrm{~g}$, birth length of $47 \mathrm{~cm}$ and a head circumference of $34 \mathrm{~cm}$. Apgar scores at 5 and $10 \mathrm{~min}$ were 9 and 10 , respectively. Newborn screening results were normal including that for MSUD.

On the day of delivery nutritional leucine intake was reduced to $200 \mathrm{mg} /$ day due to concerns about postpartum catabolism and protein turnover associated with uterus involution. The dietary protocol with details on food intake on that day is shown in Additional file 3: Table S3. Oral intake, especially supplementation of the BCAA-free amino acid mixture was possible few hours after delivery. As the patient was in a good condition 

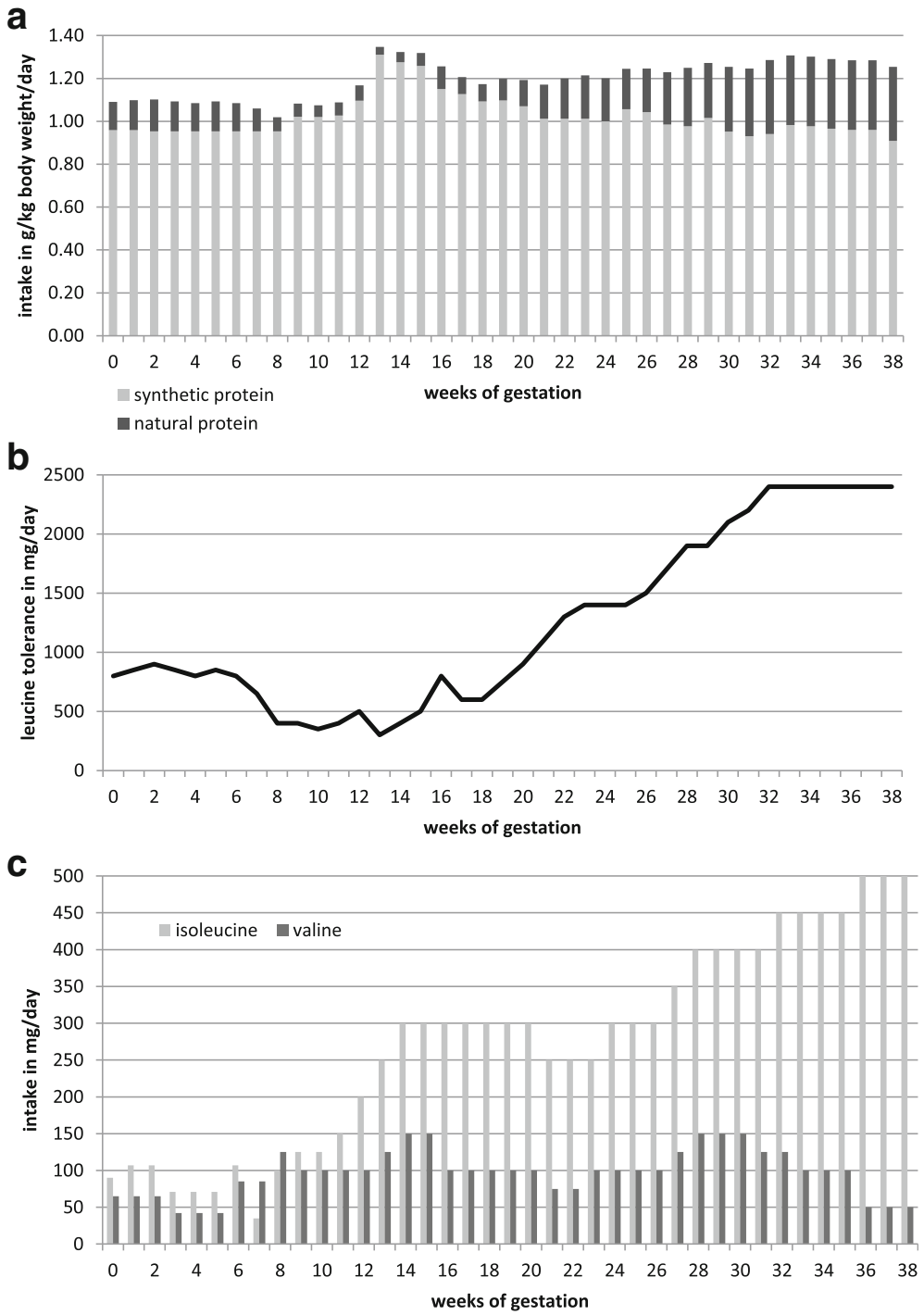

Fig. 1 Details of dietary prescriptions during pregnancy. a Intake of total protein, natural protein and synthetic protein. b Leucine tolerance. c Supplementation of isoleucine and valine

and able to take the targeted caloric amount orally, parenteral nutrition was already reduced to 50 and 25\% within the following 3 days, and could be stopped on day 5 after birth. BCAA concentrations were measured daily during the postpartum period, and BCAA intake (protein intake, isoleucine and valine supplementation) was adjusted accordingly. Vigilance was checked every $8 \mathrm{~h}$, and blood gases, electrolytes and glucose levels were monitored 2-3 times per day as were ketone bodies in urine. The patient was encouraged to take additional nonprotein calories orally from food and beverages. Lactation was well-established, and dietary leucine intake was gradually increased. The patient could be discharged from hospital on day 7 postpartum. The clinical course during breastfeeding remained stable with leucine levels ranging between 91 and $340 \mu \mathrm{mol} / \mathrm{L}$. The leucine tolerance during lactation was $1700 \mathrm{mg} /$ day (at 2 months after birth), around twice the pre-pregnancy intake. Her weight postpartum decreased by $9 \mathrm{~kg}$ within 2 months. Infant growth and development was normal at 7 months (body length $66 \mathrm{~cm}$ (22nd percentile), body weight $7460 \mathrm{~g}$ (40th percentile), head circumference $43 \mathrm{~cm}$ (47th percentile) and BMI $17,1 \mathrm{~kg} / \mathrm{m}^{2}(62 \mathrm{nd}$ percentile)).

\section{Discussion and conclusions}

Adult patients with inborn errors of metabolism are a relatively new phenomenon. Medical progress with respect to newborn screening, early diagnosis and medical treatment including dietary management has resulted in an increasing number of patients with inborn errors of metabolism who nowadays reach child-bearing age. However, experience in the management of pregnancy, 


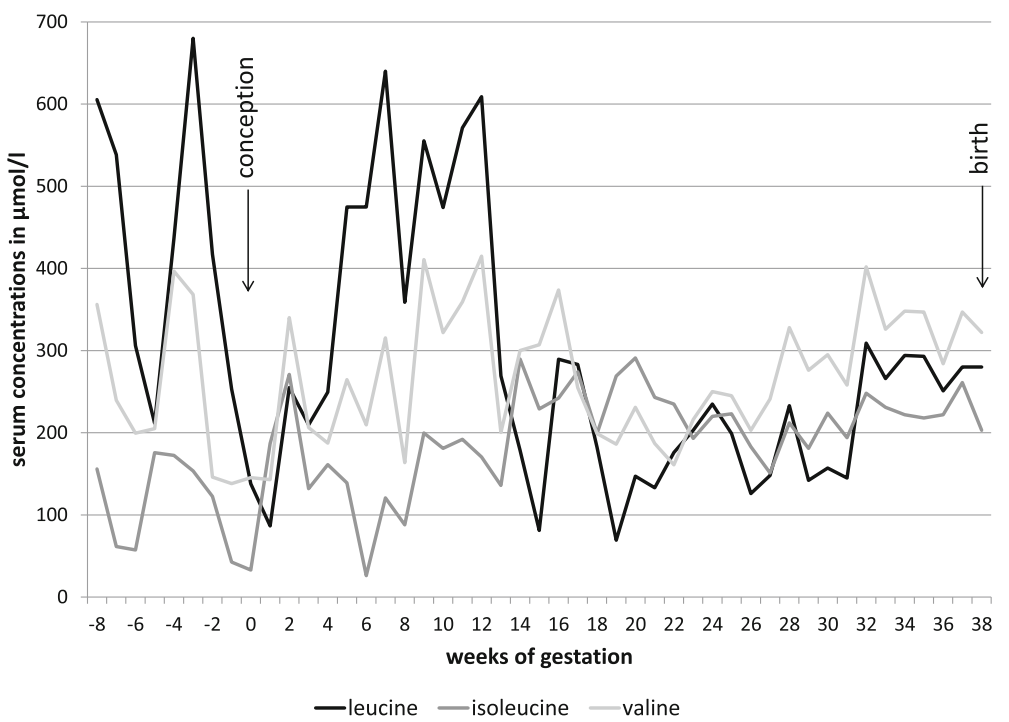

Fig. 2 Concentrations of branched-chain amino acids in serum during pregnancy

delivery and lactation is still limited for most disorders. Only nine cases of pregnancy in classical MSUD patients have been reported so far [4-10]. Details on these cases are displayed in Table 1. All were managed successfully and resulted in healthy offspring. Although there may be a publication bias in favor of cases with favorable outcome, the experience available so far suggests that pregnancy with successful outcome can be achieved.

It is known that pregnancy may be a challenge in the management of MSUD requiring careful monitoring and regular dietary adjustments. The pregnancy in our patient became known as early as week 7 of gestation. Amino acid concentrations were monitored at least weekly throughout pregnancy and lactation. Despite excellent compliance metabolic control was not easy to achieve during the first trimester and leucine levels were often above the target range, possibly due to an inadequate caloric intake. Grossly elevated leucine levels throughout the whole course of pregnancy have also been reported in 2 cases by Tchan et al. due to compliance problems [10]. Evidence on potential harmful effects of high concentrations of leucine, 2-oxoiocaproic acid and other MSUD related metabolites is very limited. Data from animal models are not available. However, all reported pregnancies with MSUD resulted in healthy newborns, making a teratogenic effect of MSUD metabolites unlikely. Nevertheless, subtle long-term effects cannot be excluded as none of the children was followed for more than 3 years, and standardized developmental testing was only performed in one infant at 7 months [4]. As it has been shown for healthy pregnancies as well as for MSUD pregnancies that amino acid concentrations in cord blood are 1.5 fold the maternal levels owing to active transport via the placenta it is recommendable to keep BCAA levels in pregnant MSUD patients as close to the normal range as possible $[5,8,11]$.
As known from other cases leucine tolerance increased progressively from the second trimester. This can possibly be explained by both enhanced protein synthesis due to fetal growth and new capacity for BCAA metabolism gained from the liver of the heterozygous fetus [8]. In our case, leucine intake could be increased to $2400 \mathrm{mg} /$ day prior to delivery, which was about 3 times the prepregnancy leucine tolerance. To minimize metabolic stress during delivery and the postpartum period leucine intake was reduced to $200 \mathrm{mg} /$ day on the day of delivery and subsequently titrated up to $1700 \mathrm{mg}$ /day during lactation based on BCAA concentrations in serum. The nutritional therapy was based on the recommendations published by Frazier et al. [12].

To provide maximal safety for mother and child we recommended that our patient should give birth in a specialized metabolic center. Primary Cesaerean section was proposed due to geographical distance between the patient's place of residence and our university hospital. Alternatively, planned induction of labour can also be considered in case of good compliance of the patient and geographical proximity to the obstetric/ metabolic centre. Previous reports have shown that mothers with MSUD are at risk of developing high blood leucine concentrations especially in the postpartum period, possibly due to uterine involution. Three patients reported in the literature had leucine concentrations of more than $1000 \mu \mathrm{mol} / \mathrm{L}$ on day $9-10$ postpartum $[5,8,10]$, demonstrating that BCAA levels should be closely monitored during this period. Only one patient showed neurologic symptoms including dizziness and lethargy. In all cases leucine levels dropped spontaneously, and infusion therapy was not necessary. There is one report of maternal death at day 51 postpartum, however, it is unclear whether 


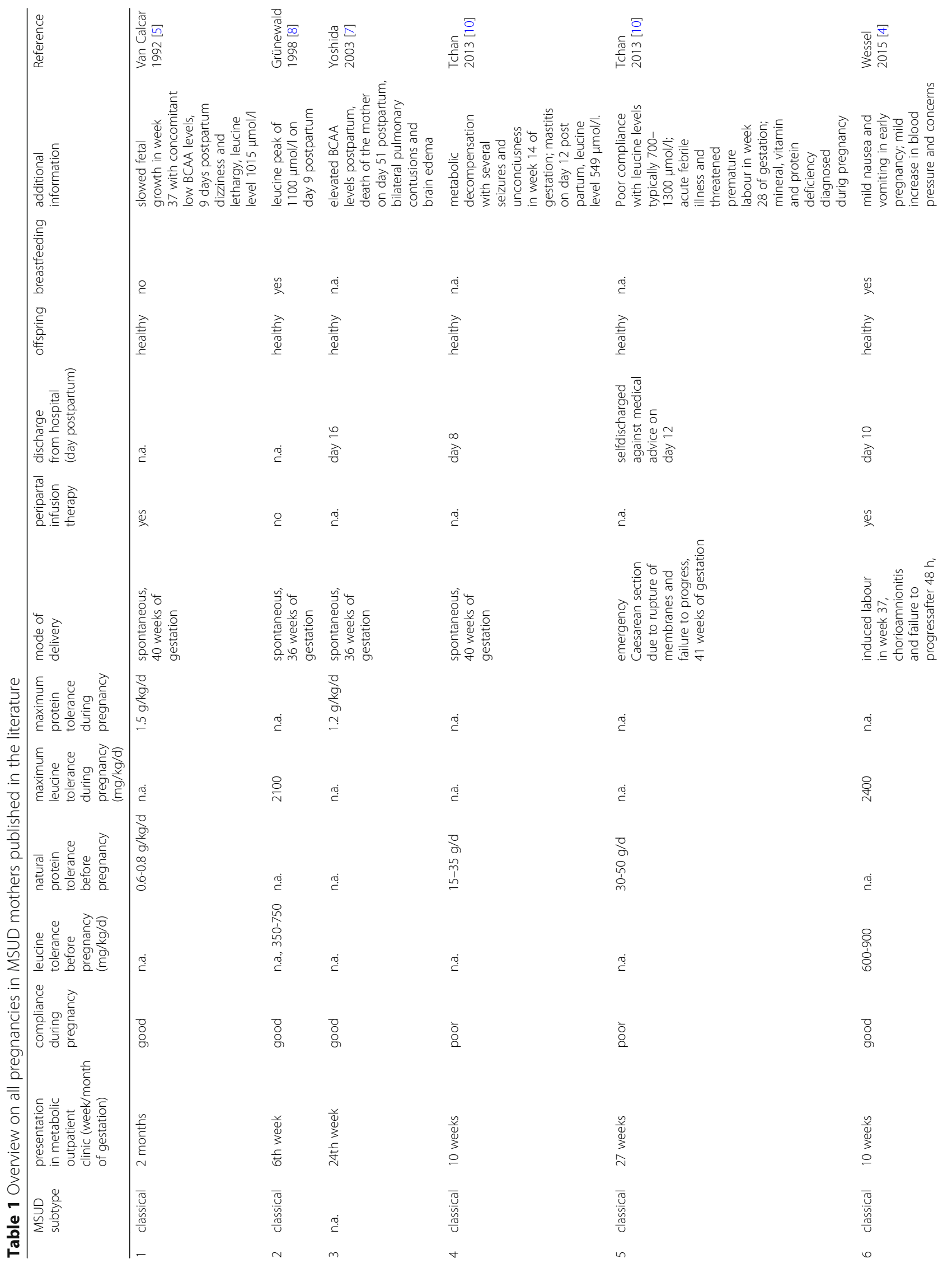




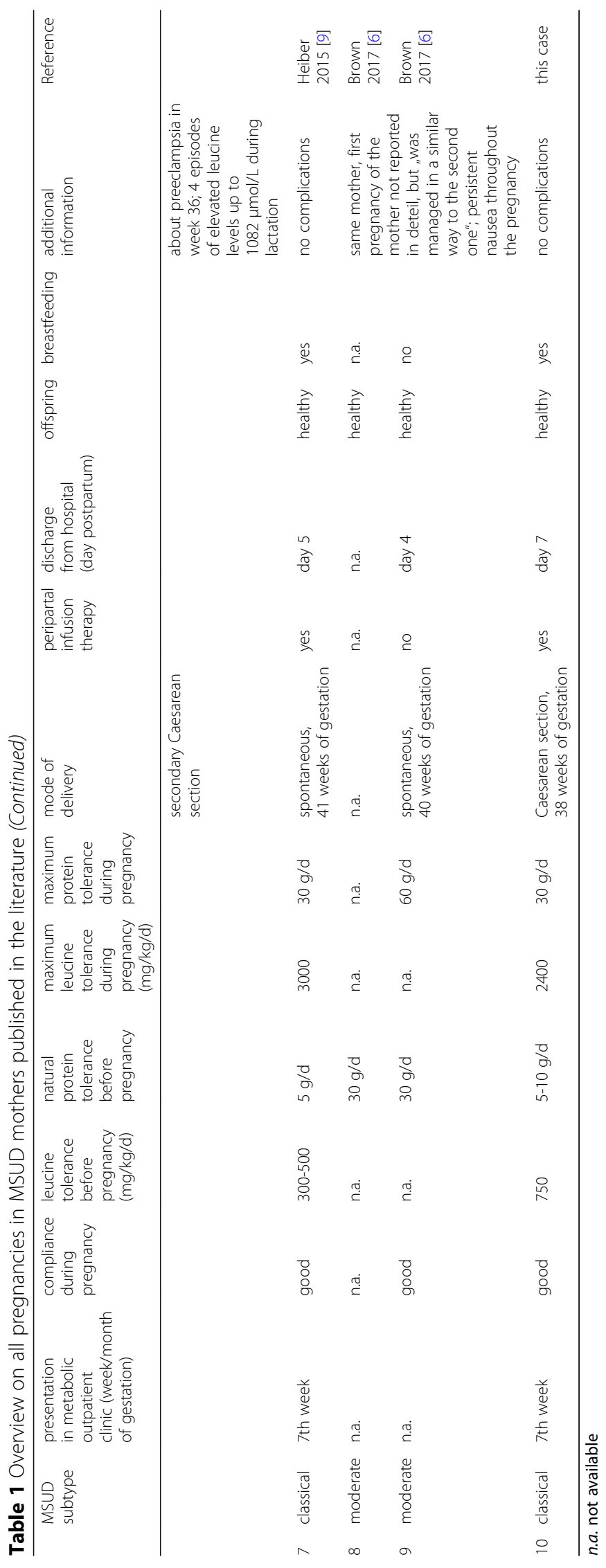


the patient died of metabolic decompensation or domestic violence [7].

Our case demonstrates that successful management of pregnancy in classical MSUD is possible. Metabolic decompensations can be prevented by an individually tailored treatment plan including protein restriction, adequate caloric supply and prevention of catabolism. Optimal management for pregnant patients with inborn errors of metabolism requires close collaboration of all specialists involved and delivery should be arranged in a center with experience in the treatment of inborn errors of metabolism.

\section{Additional files}

Additional file 1: Table S1. MSUD diet prior to conception (leucine intake $600 \mathrm{mg} /$ day). (DOCX $15 \mathrm{~kb}$ )

Additional file 2: Table S2. MSUD diet at the end of pregnancy (leucine intake $2400 \mathrm{mg} /$ day). (DOCX $15 \mathrm{~kb}$ )

Additional file 3: Table S3. MSUD diet at the day of delivery (leucine intake $200 \mathrm{mg} /$ day, additional to a high-caloric infusion therapy). (DOCX $15 \mathrm{~kb}$ )

\section{Abbreviations}

BCAA: Branched-chain amino acids; MUSD: Maple syrup urine disease

\section{Acknowledgements}

We thank the patient and her family for everything we were allowed to learn from their experience and are grateful for their consent to publish this case.

\section{Availability of data and materials}

Data sharing is not applicable to this article as no datasets were generated or analysed during the current study. Details on the patient treatment are documented in the medical records of the hospital documentation system, but cannot be shared for privacy reasons.

\section{Authors' contributions}

All authors were involved in the care of the patient as part of the metabolic team. They were involved in tailoring the management plan for the peripartal period. SG drafted the manuscript and analyzed the available literature data. All authors read and approved the final manuscript.

\section{Ethics approval and consent to participate}

Ethics approval not applicable as no interventions apart from routine treatment were performed. The patient consented to the publication of this case report.

\section{Consent for publication}

The patient gave her consent for the publication of this case report.

\section{Competing interests}

The authors declare that they have no competing interests.

\section{Publisher's Note}

Springer Nature remains neutral with regard to jurisdictional claims in published maps and institutional affiliations.

Received: 30 January 2018 Accepted: 27 April 2018

Published online: 12 May 2018

\section{References}

1. Nellis MM, Kasinski A, Carlson M, Allen R, Schaefer AM, Schwartz EM, et al. Relationship of causative genetic mutations in maple syrup urine disease with their clinical expression. Mol Genet Metab. 2003;80:189-95.
2. Strauss KA, Puffenberger EG, Morton DH. Maple syrup urine disease. In: Adam MP, Ardinger HH, Pagon RA, Wallace SE, Bean $L$, Mefford HC, et al, editors. GeneReviews $\left({ }^{(}\right)$. Seattle: University of Washington; 1993. http:// www.ncbi.n/m.nih.gov/books/NBK1319/. Accessed 4 Oct 2017.

3. Puffenberger EG. Genetic heritage of the old order Mennonites of southeastern Pennsylvania. Am J Med Genet C Semin Med Genet. 2003;121C:18-31.

4. Wessel AE, Mogensen KM, Rohr F, Erick M, Neilan EG, Chopra S, et al. Management of a Woman with Maple Syrup Urine Disease during Pregnancy, delivery, and lactation. JPEN J Parenter Enteral Nutr. 2015;39:875-9.

5. Van Calcar SC, Harding CO, Davidson SR, Barness LA, Wolff JA. Case reports of successful pregnancy in women with maple syrup urine disease and propionic acidemia. Am J Med Genet. 1992;44:641-6.

6. Brown J, Tchan M, Nayyar R. Maple syrup urine disease: tailoring a plan for pregnancy. J Matern-Fetal Neonatal Med. 2018;31:1663-6.

7. Yoshida S, Tanaka T. Postpartum death with maple syrup urine disease. Int J Gynaecol Obstet Off Organ Int Fed Gynaecol Obstet. 2003;81:57-8.

8. Grünewald S, Hinrichs F, Wendel U. Pregnancy in a woman with maple syrup urine disease. J Inherit Metab Dis. 1998;21:89-94.

9. Heiber S, Zulewski H, Zaugg M, Kiss C, Baumgartner M. Successful pregnancy in a woman with maple syrup urine disease: case report. JIMD Rep. 2015;21:103-7.

10. Tchan M, Westbrook M, Wilcox G, Cutler R, Smith N, Penman R, et al. The management of pregnancy in maple syrup urine disease: experience with two patients. JIMD Rep. 2013;10:113-7.

11. Ghadimi H, Pecora P. Free amino acids of cord plasma as compared with maternal plasma during pregnancy. Pediatrics. 1964;33:500-6.

12. Frazier DM, Allgeier C, Homer C, Marriage BJ, Ogata B, Rohr F, et al. Nutrition management guideline for maple syrup urine disease: an evidence- and consensus-based approach. Mol Genet Metab. 2014;112:210-7.

\section{Ready to submit your research? Choose BMC and benefit from:}

- fast, convenient online submission

- thorough peer review by experienced researchers in your field

- rapid publication on acceptance

- support for research data, including large and complex data types

- gold Open Access which fosters wider collaboration and increased citations

- maximum visibility for your research: over $100 \mathrm{M}$ website views per year

At BMC, research is always in progress.

Learn more biomedcentral.com/submissions 